\title{
The influence of cultural context in managerial decision-making: legitimacy views of Finnish and Italian managers
}

\section{Johanna Kujala*}

Tampere University, Kanslerinrinne 1, FI-33014, Finland

Email: johanna.kujala@tuni.fi

*Corresponding author

\section{Valentina Battista}

Cranfield University School of Management, College Road, Cranfield MK43 0AL Bedford, UK

Email: v.battista@cranfield.ac.uk

\section{Lorenzo Lucianetti}

Department of Management and Business Administration,

University of Chieti and Pescara,

Viale Pindaro 42 - 65127 Pescara, Italy

Email: lorenzo.lucianetti@unich.it

\section{Anni Paavilainen}

Tampere University,

Kanslerinrinne 1, FI-33014, Finland

Email: anni.paavilainen@tuni.fi

\begin{abstract}
This study examines the influence of cultural context in managerial decision-making by comparing the legitimacy views of Finnish and Italian business managers. In the business context, managers often make decisions based on economic interests only; but for moral decisions, other means of legitimacy are required. Although both Finland and Italy are members of the European Union (EU), they differ in terms of cultural dimensions. The study contributes to previous research on managerial decision-making by showing, with a qualitative approach, that the differences between Finnish and Italian managers decision-making relate to the different ways of using legitimacy combined with the short-term vs. long-term orientation of the culture. Finnish managers use the property and perception views of legitimacy that reflect the short-term orientation and normative dimension of the culture, while Italian managers rely on a process view of legitimacy reflecting the long-term orientation.
\end{abstract}

Keywords: cultural comparison; moral dilemma; legitimacy; decision-making. 
Reference to this paper should be made as follows: Kujala, J., Battista, V., Lucianetti, L. and Paavilainen, A. (2021) 'The influence of cultural context in managerial decision-making: legitimacy views of Finnish and Italian managers', Int. J. Human Resources Development and Management, Vol. 21, Nos. 2/3, pp.149-164.

Biographical notes: Johanna Kujala is a Professor of Management and Organizations, the Vice-Dean for Research, and the Director of the RESPMAN Research Group at the Tampere University. She is the PI of the B2N Business to Nature Research Project funded by the Academy of Finland, and a WP leader in the CICAT2025 Circular Economy Catalysts research project funded by the Finnish Strategic Research Council. She has acted as a Visiting Scholar in the University of Virginia and the University of Chieti and Pescara, and published over 50 scholarly articles. Her current research interests focus on circular economy, stakeholder engagement and value-creation, and corporate responsibility and sustainability.

Valentina Battista is a Lecturer in Human Resource Management at the School of Management of Cranfield University (UK). Her research focuses on investigating contemporary practices of people management with a particular focus on performance.

Lorenzo Lucianetti is a Professor of Business Administration and the Director of Undergraduate Studies in Economics and Management at the University of Chieti and Pescara, Italy. He is also a Visiting Research Fellow at the University of Cranfield, UK and a DBA Supervisor at the Liverpool University (UK). His research has appeared in refereed journals such as the Academy of Management Journal, the Journal of Applied Psychology, the Journal of Operations Management, the Journal of Organizational Behavior, the Journal of Business Ethics and the International Journal of Operations and Production Management and Management Accounting Research.

Anni Paavilainen is a Master's student of Responsible Business and Bachelor of Business Management. She is working on her Master's thesis on circular economy. Her research interests focus on circular economy, corporate collaboration and sustainability.

This paper is a revised and expanded version of a paper entitled 'Legitimating Managerial Moral Decisions: A Comparison between the Finnish and Italian Cases' presented at International Conference on Management Cases 2017, BIMTECH Campus, Greater Noida, India, 30 November-1 December 2017.

\section{Introduction}

Research on managerial decision-making has a long history, with ample studies especially in regard to ethics (Craft, 2013; Loe et al., 2000; O'Fallon and Butterfield, 2005). The cultural context is an important factor that affects individuals' moral attitudes and moral evaluations (Ferrell and Gresham, 1985; Hunt and Vitell, 1986). In recent years, many studies have compared moral decision-making in different cultural contexts (Fok et al., 2016; Oumlil and Balloun, 2009; Payne et al., 2016; Sims, 2009). Most of these studies, however, are based on quantitative data and address the differences between Asian and US cultures, whereas qualitative research and comparisons between 
different European countries are rare. Yet, there are significant differences between European countries in terms of culture and economy and therefore it is important to understand how managers' moral decision-making differs in the area.

The purpose of this study is to examine how cultural context influences managerial decision-making by comparing the ways managers legitimate their moral decisions in Finland and Italy. In the business context, managers are often criticised for making their decisions based on economic interests only, but in moral decisions, other means of legitimacy are required. In this study, the legitimacy theory is used in the examination of the differences in managers' moral decision-making. Legitimacy is important because it influences how organisations and individuals behave and perform (Deephouse et al., 2017). Although, both Finland and Italy are members of the EU, there are significant differences between them in terms of culture, economy and national value system. According to Hofstede (1985), these two contexts represent almost totally opposite cultural dimensions, especially on the dimension of masculinity and femininity but also in pragmatism, indulgence, power distance and uncertainty avoidance. Therefore, the authors aim to examine the differences in managerial legitimation between these two countries in order to understand how cultural differences influence managerial decision-making.

The study adds two contributions to previous research. First, the authors respond to the call for qualitative research of moral decision-making as it has been argued that understanding managerial moral decision-making can be considerably increased by qualitative research (Brand and Slater, 2003). A more realistic picture can be obtained from qualitative studies of decision-making and new perspectives can be gained for theory development (Lehnert et al., 2016).

Second, the study adds to the previous decision-making studies by examining how legitimacy is understood in managerial decision-making in diverse cultural environments by studying and comparing managerial decision-making processes in Finland and Italy.

We use Hofstede's (1985) dimensions of national culture to describe the differences between these two cultures, and discuss the differences in managerial decision-making in relation to cultural differences.

The rest of the article is organised as follows. In the next sections, the authors, first, discuss the Hofstede's dimensions of national culture in Finland and in Italy (Hofstede Insights, 2019). After that, a discussion on the legitimacy argumentation and the ways it advises the empirical examination is presented. Then, the research methods are described and the findings of the study are presented. Finally, the authors discuss the differences between the Finnish and Italian managerial decision-making and present the theoretical contributions and managerial implications of the study.

\section{Cultural differences}

According to Hofstede (1984), national cultures can be described along six cultural dimensions: power distance, individualism, masculinity, uncertainty avoidance, long-term orientation and indulgence. Hofstede's dimensions have been widely used in various fields of management studies, and it provides a common ground for comparisons of cultural differences (Lu et al., 1999). 
In short, power distance refers to the degree of accepting the fact "that power in institutions and organizations is distributed unequally" [Hofstede, (1985), p.347]. In high power distance cultures, the inequality of power distribution between superiors and subordinates is natural and superiors have special privileges, while low power distance cultures do not tolerate class distinctions and prefer democratic participation (Hofstede et al., 2005). Both Finland (score 33 in Hofstede's 6D framework) and Italy (score 50) are regarded to have low power distance, although the Finnish culture is regarded to be somewhat more equal and less hierarchical (Hofstede Insights, 2019).

Individualism refers to pursuing self-interests, individual expression, emphasising ' $\mathrm{I}$ ' over 'we' and having loose tights between individuals and the society (Hofstede, 1984; Triandis, 1995). In individualist societies, people are responsible for themselves and their direct family only, while in collectivist societies, people have a strong feeling of belonging to groups that take care of them. Both Finland (score 63) and Italy (score 76) are individualist societies, although Italy is considered to be even more 'me' centred. (Hofstede Insights, 2019)

Masculinity is understood as "a preference for achievement, heroism, assertiveness, and material success" [Hofstede, (1985), p.348]. A masculine society is driven by competition, achievement and success, while feminine society emphasises caring for others and quality of life. Finland (score 26) is considered a feminine society, while Italy (score 70) is a masculine society (Hofstede Insights, 2019.)

Uncertainty avoidance is defined as "the degree to which members of a society feel uncomfortable with uncertainty and ambiguity, leading them to support beliefs promising certainty and to maintain institutions protecting conformity" [Hofstede, (1984), p.347]. In cultures with high uncertainty avoidance, rules, hard work and punctuality are valued and people not comfortable in ambiguous situations. Both Finland (score 59) and Italy (score 75) have high preference for avoiding uncertainty meaning (Hofstede Insights, 2019).

Long-term orientation refers to the connection between the past, the present and the future. Low scores in this dimension relates to viewing societal change with suspicion, while high scores mean more pragmatic, future oriented culture (Hofstede et al., 2005). While Finland (score 38), represents a normative culture that respects traditions and focus on achieving quick results, Italy (score 61) represents a more pragmatic society where people believe that truth depends very much on situation, context and time and are adaptive to change (Hofstede Insights, 2019).

Finally, indulgence relates to the level of controlling desires and impulses. Indulgence means relatively weak control and restraint relatively strong control (Hofstede et al., 2005). In this dimension, Finland (score 57) is considered as an indulgent country, where people generally want to enjoy life and have fun, have a positive attitude and a tendency towards optimism. On the contrary, Italy (score 30) is a more restraint culture, with a tendency to pessimism, social control and limiting desires (Hofstede Insights, 2019).

To sum, Finland and Italy are both individual cultures that have high uncertainty avoidance and low power distance. However, the Finnish and Italian cultures differ in terms of masculinity, long-term orientation and indulgency. Finland is considered a feminine, traditional and indulgent society and Italy, a masculine, pragmatic and restraint society. 


\section{Legitimacy argumentation}

In general, legitimacy refers to the understanding that the actions of a person or an organisation are accepted, proper and in accordance with the norms, values and beliefs of some socially constructed system (Suchman, 1995). According to the legitimacy theory, organisations have to earn their right to exist by gaining social acceptance and legitimacy from the society around them (Deegan, 2006). While legitimacy has been subject to ample of research in the field of management and organisation studies, research on how legitimacy is understood in diverse environments and among different audiences is called for (Suddaby et al., 2017).

This study follows Treviño et al. (2014) who identified four different ways of legitimacy argumentation:

1 cognitive legitimacy

2 instrumental legitimacy

3 relational legitimacy

4 moral legitimacy.

Cognitive legitimacy involves acceptance of an authority and is based on the idea that the action is legitimate when it fits in a larger belief system and its assumptions of how one should behave in a certain situation. Cognitive legitimacy does not have an explicit connotation of moral approval but rather is based on comprehensibility and 'taken-for-grantedness' of the correct behaviour (Treviño et al., 2014).

Instrumental legitimacy rests on the notion of exchange and the support for the argumentation is based on the consequences that follow as well as on the benefits the action brings. Instrumental legitimacy has also been called as pragmatic legitimacy, since it is often the case that the exchange relationship benefits both parties in some way, especially so in the business context (Treviño et al., 2014). Using the benefits that follow from an action in managerial argumentation refers thus to instrumental legitimacy. From the instrumental point of view, a legitimacy challenge may occur when the action is not seen to lead to expected consequences.

Relational legitimacy is based on the social needs of human beings that enforce the desire to belong to a group and relate with other human beings. According to Treviño et al. (2014) relational legitimacy is gained when "one affirms another person's social identity and reinforces their self-worth, generally through identification with the group or organization."

Moral legitimacy refers to the idea that the action is congruent with the prevailing value systems and moral conviction (Treviño et al., 2014). In more general terms, moral legitimacy relates to the arguments that refer to ethical behaviour and, thus, to the person's understanding of what is the right and what is the wrong thing to do.

Suddaby et al. (2017) have identified three different ways of using legitimacy:

1 legitimacy as property

2 legitimacy as process

3 legitimacy as a perception. 
The property view refers to the idea that legitimacy is a resource or a capacity. Many researchers refer to legitimacy as an asset that can be gained (George et al., 2006) or lost (Chen et al., 2006). According to the property view, legitimacy helps an organisation to respond to its stakeholders' expectations and needs, and therefore, legitimacy is seen as an organisational or field level concept that occurs as a situational fit between the organisational attributes and external expectations (Suddaby et al., 2017).

The process view sees legitimacy as an interactive process between various actors, and therefore, uses the term 'legitimation' rather than legitimacy (Suddaby et al., 2017). The process view relates to the notions of organisations as socially constructed entities which exist through constant social interactions (Berger and Luckmann, 1966) and language use (Foucault, 2002). The process view refers to a more reproductive, collaborative and dynamic understanding of legitimacy as the property view (Suddaby et al., 2017) and thereby, the complexities, ambiguities and contradictions around legitimation gain interest (Joutsenvirta and Vaara, 2009).

The perception view sees legitimacy as a social judgement or evaluation between an individual and a group, an organisation or a society (Suddaby et al., 2017). Similarly, to the process view, the perception view understands legitimacy as a socially constructed process but emphasises on the role of individuals in the social construction of legitimacy. Opposite to the property and process views, the perception view sees individuals as subjects or as the decision makers who are evaluating or judging the situation (Bitektine and Haack, 2015; Tost, 2011). Therefore, the focus is on the perceptions, judgements and actions of individuals and how they are influenced by the collective-level institutionalised judgements (Suddaby et al., 2017).

Patriotta et al. (2011) argued that rhetoric and discourse are important in how organisations and their managers gain and maintain legitimacy. Thus, legitimacy can be traced by paying attention to the managerial language use, i.e., the ways by which managers talk about things. Following the idea of the importance of language in establishing legitimacy suggested by Patriotta et al. (2011) and the various dimensions of legitimacy presented by Treviño et al. (2014), the authors planned the data collection and analysis as explained in the next section of this article.

\section{Data collection and analysis}

The data for the study were collected with a survey research targeted to Finnish and Italian managing directors of industrial companies with more than 100 employees in 2014. In Finland, the data were collected by means of a census through a postal survey with mailing information from Statistics Finland. In Italy, the data were collected from 1,200 managers randomly selected from Amadeus - Bureau Van Dijk (AIDA, a source of financial and other information of firms operating in Italy).

A moral dilemma called 'dismissal of an employee' was used to collect the data. This dilemma was originally developed based on exploratory interviews of Finnish business managers and was tested in several empirical researches on moral decision-making in Finland and Italy (Kujala, 2001; Kujala et al., 2011). In the survey questionnaire, the dilemma was described as follows:

"Because of the company's financial situation, the CEO needs to dismiss an elderly long-time employee with only three years to his/her pension. Since 
there are no other easy savings targets, the CEO decides to dismiss the employee."

The respondents were asked to respond to an open-ended question of what they would have done in a similar situation and why. A total of 62 managers from Finland and 220 managers from Italy responded, representing a response rate of $11.6 \%$ and $23.5 \%$, respectively.

To support the data analysis, an empirical research question was defined: what is considered legitimate and how is legitimacy argued for in the responses? The authors followed a theory-driven qualitative content analysis (Hsieh and Shannon, 2005) and argumentation analysis (Rieke et al., 2013) and noted the various dimensions of legitimacy. The analysis process followed the idea of first-order and second-order analysis given by Gioia et al. (2013). The first-order analysis consisted of classifying the responses into three response groups: agreeing, disagreeing, and uncertain responses and into four legitimacy categories: cognitive, instrumental, relational and moral legitimacy. The second-order analysis comprised combining the findings from the Finnish and Italian datasets, finding the differences and similarities and discussing the results in light of previous research and theory.

\section{Findings}

All the responses were first classified according to whether managers agreed with the CEO's dismissal action in the dilemma (Table 1). This was done in order to find out the differences between the two datasets. In the Finnish data, $52 \%$ of the respondents agreed with the manager's dismissal conduct in the dilemma, while only $25 \%$ of the Italian respondents agreed with it. In the Finnish data, $23 \%$ of the respondents did not agree with the manager's conduct, whereas more than half of the Italian managers $(56 \%)$ did not agree with the dismissal decision of the CEO. And finally, $26 \%$ of the Finnish and 19\% of the Italian respondents were uncertain of what they would have done in the situation. This evidence suggests that in Italy, the choice to dismiss an employee three years before his or her retirement is seen as less legitimate than in Finland.

Table 1 Agreeing, disagreeing and uncertain responses in the two datasets

\begin{tabular}{cccccc}
\hline Dataset & & Agreeing & Disagreeing & Uncertain & Total \\
\hline Finland & $\mathrm{n}$ & 32 & 14 & 16 & 62 \\
& $\%$ & 52 & 23 & 26 & 100 \\
Italy & $\mathrm{n}$ & 54 & 124 & 42 & 220 \\
& $\%$ & 25 & 56 & 19 & 100 \\
\hline
\end{tabular}

Source: Compiled by the authors

To find out more precisely how managers legitimate their decisions, the responses were next classified into four categories, cognitive, instrumental, relational and moral argumentation (Table 2). Eleven out of the 16 uncertain responses in the Finnish data were so short that their way of legitimation could not be analysed. Therefore, the total amount of responses in the Finnish data is 51 instead of the previous 62. 
Table 2 Cognitive, instrumental, relational and moral legitimacy in the two datasets

\begin{tabular}{ccccccc}
\hline Dataset & & Cognitive & Instrumental & Relational & Moral & Total \\
\hline \multirow{2}{*}{ Finland } & $\mathrm{n}$ & 19 & 17 & 10 & 5 & 51 \\
& $\%$ & 37 & 33 & 19 & 10 & 100 \\
\multirow{3}{*}{ Italy } & $\mathrm{n}$ & 106 & 48 & 47 & 19 & 220 \\
& $\%$ & 48 & 22 & 21 & 9 & 100 \\
\hline
\end{tabular}

Source: Compiled by the authors

In both datasets, cognitive legitimacy was used most often for argumentation (Finland $37 \%$, Italy $48 \%$ ). Instrumental legitimacy was the second most often (Finland $33 \%$, Italy $22 \%$ ) and relational legitimacy was the third most often (Finland 19\%, Italy 21\%) used method. Moral legitimacy was used clearly less often than the others (Finland 10\%, Italy $9 \%$ ).

\subsection{Cognitive legitimacy}

To examine more closely the argumentation that managers use in their decision-making, an analysis of the content of the responses was carried out for all four legitimation categories (Table 3).

Table 3 Cognitive legitimacy in the two datasets

\begin{tabular}{|c|c|c|}
\hline Dataset & Description & Example quotes \\
\hline \multirow{3}{*}{$\begin{array}{l}\text { Finnish data } \\
19 \text { responses } \\
(37 \%)\end{array}$} & \multirow{3}{*}{$\begin{array}{l}\text { The decision is } \\
\text { legitimated with the } \\
\text { respondent's } \\
\text { authority position. }\end{array}$} & "Would have dismissed." \\
\hline & & $\begin{array}{l}\text { "I wouldn't have dismissed but rather would have } \\
\text { looked for other ways." }\end{array}$ \\
\hline & & "I can't take a stand without knowing all of the facts." \\
\hline \multirow{3}{*}{$\begin{array}{l}\text { Italian data } \\
106 \text { responses } \\
(48 \%)\end{array}$} & \multirow{3}{*}{$\begin{array}{l}\text { The decision is } \\
\text { evaluated based on } \\
\text { cognitive reasoning } \\
\text { about the CEO's } \\
\text { authority position, } \\
\text { which would enable } \\
\text { him/her to search for } \\
\text { other ways to save } \\
\text { money. }\end{array}$} & $\begin{array}{l}\text { "I would have acted in the exact same way, } \\
\text { dismissing the employee." }\end{array}$ \\
\hline & & $\begin{array}{l}\text { "As the CEO, I would have reduced my salary and } \\
\text { worked harder to find a solution that didn't require } \\
\text { dismissing the employee." }\end{array}$ \\
\hline & & $\begin{array}{l}\text { "The action cannot be evaluated without knowing the } \\
\text { alternatives and the consequences." }\end{array}$ \\
\hline
\end{tabular}

Source: Compiled by the authors

In the Finnish data, cognitive legitimacy was used more often in the agreeing than in the disagreeing responses (agreeing 13, disagreeing 6). In the agreeing responses, the leader's view was seen to legitimate the decision. Most of the responses that used cognitive legitimacy were very short and the legitimacy of the decision was built on the manager's authority. For example, 'the same decision' or 'would have dismissed'. Interestingly, the disagreeing and uncertain responses were longer than the agreeing responses. In the disagreeing responses, managers assumed there must be other ways to cut costs: "I wouldn't have dismissed but rather would have looked for other ways." In the uncertain responses, managers stated that the situation was hypothetic and that more 
information was needed to find the right solution: "I can't take a stand without knowing all of the facts."

In the Italian data, cognitive legitimacy was used slightly more in the case of agreeing on responses than in disagreeing. In the agreeing responses, the decision was legitimated by the CEO's authority. Typical responses included the following: "I would have acted in the exact same way, dismissing the employee" or "I would have done the same." Conversely, in the disagreeing responses, managers used cognitive reasoning to counter that, given the authority position of the CEO; he/she should search for other ways to reduce cost and save money, avoiding the dismissal. This evidence emerged in many of the responses, most of which proposed alternative solutions such as: "As the CEO, I would reduce my salary and work harder to find a solution that didn't require dismissing the employee." Or "As the CEO, I would have followed the example of other leaders I know, who reduced their salary and the salary at the top-level positions." In the uncertain responses, managers did not take any position but rather required more information: "The action cannot be evaluated without knowing the alternatives and the consequences."

\subsection{Instrumental legitimacy}

Instrumental legitimacy was the second most common type of argumentation in both datasets. In the Finnish data, it was used more often in agreeing than in the disagreeing responses. In the agreeing responses, the decisions were often legitimised based on their instrumental value (the economic continuity of the firm): "If the impact of savings is critical for the company, I would have acted similarly." The instrumental advantage the company receives legitimates the decision and the dismissal is seen as legitimate if, for example, it promotes the economic continuity of the company. However, instrumental legitimacy was also used in some disagreeing responses in the Finnish dataset: "I would have studied all of the ways to reach the savings targets; dismissal is the last resort if the person in question is a valuable employee." In this example, the decision is based on the instrumental argumentation of seeing the employee as a valuable resource for the company. In uncertain responses, the managers often expressed that instrumental argumentation can be used in many ways, but economic interest was often the overruling reason for making the final decision: "It depends on whether the savings is compelling."

In the Italian data, the dismissal decision was legitimated by the company's interests: "The interests of the company are more important than those of an individual. Thus, if it is in the best interest of the company, you must make a decision like that." Or even: "Surely if this were the only possible solution in a difficult business moment, I would not hesitate!" In the disagreeing responses, however, managers' evaluation and disagreement with the decision were based on the impact of this choice on the other employees in terms of personal motivation, trust towards the organisation and in general, organisational climate. Managers said: "I would never dismiss. It would create discontent among employees, and that would affect the organizational climate." Or: "If the performance of the employee is positive, you should not dismiss him. The expertise of the human resource, together with the experience, is part of the organisation. Moreover, you should consider the effect of this similar choice on the motivation of the other employees." This evidence suggests that, employees are considered part of the organisation and that their well-being and a good organisational climate are understood as fundamental to the company's success. Finally, in the uncertain responses, managers said: "Hard to say. If 
the situation is really critical, I would do the same, but to dismiss would be my last resort." This quote shows that the manager may consider dismissal if required for the company's success. Table 4 depicts how the instrumental legitimacy was used in the Finnish and Italian responses.

Table 4 Instrumental legitimacy in the two datasets

\begin{tabular}{|c|c|c|}
\hline Dataset & Description & Example quotes \\
\hline \multirow{3}{*}{$\begin{array}{l}\text { Finnish data } \\
17 \text { responses } \\
(33 \%)\end{array}$} & \multirow{3}{*}{$\begin{array}{l}\text { The instrumental } \\
\text { advantage that the } \\
\text { company receives } \\
\text { legitimates the decision. } \\
\text { The dismissal is legitimate } \\
\text { if, for example, it promotes } \\
\text { the economic continuity of } \\
\text { the company. }\end{array}$} & $\begin{array}{l}\text { "If the impact of savings is critical in terms of } \\
\text { the company, I would have acted similarly." }\end{array}$ \\
\hline & & $\begin{array}{l}\text { "I would have studied all of the ways to reach the } \\
\text { savings targets; dismissal is the last resort if the } \\
\text { person in question is a valuable employee." }\end{array}$ \\
\hline & & $\begin{array}{l}\text { "It depends on whether the savings are } \\
\text { compelling." }\end{array}$ \\
\hline \multirow[t]{3}{*}{$\begin{array}{l}\text { Italian data } \\
48 \text { responses } \\
(22 \%)\end{array}$} & \multirow{3}{*}{$\begin{array}{l}\text { The decision is evaluated } \\
\text { based on the instrumental } \\
\text { consequences for the } \\
\text { company, which involve } \\
\text { aspects such as the } \\
\text { interests of the company } \\
\text { itself but also the } \\
\text { organisational climate. }\end{array}$} & $\begin{array}{l}\text { "The company's interests are more important } \\
\text { than those of an individual. Thus, if it is in the } \\
\text { best interest of the company, you must make a } \\
\text { decision like that." }\end{array}$ \\
\hline & & $\begin{array}{l}\text { "I would never dismiss. It would create } \\
\text { discontent among employees, and that would } \\
\text { affect the organizational climate." }\end{array}$ \\
\hline & & $\begin{array}{l}\text { "Hard to say; if the situation were really critical, } \\
\text { I would do the same, but to dismiss would be my } \\
\text { last resort." }\end{array}$ \\
\hline
\end{tabular}

Source: Compiled by the authors

\subsection{Relational legitimacy}

In the Finnish data, relational argumentation was also used in agreeing, disagreeing, and uncertain responses. Generally, relational argumentation included situational factors as well as the employee's point of view. In the agreeing responses, relational argumentation was associated with age: "If the alternative is to dismiss a younger employee, I'll accept this. It naturally depends on the motivation of this older employee." The social security system of Finland was also used as a reason for agreeing to responses on the following: "I would have done similarly, there is sufficient social security in Finland, i.e. an individual won't experience hardship, but a company might unless it takes action." However, most of the responses that depended on relational argumentation were disagreeing, especially with regard to the employee's situation: "I would have searched for a solution that allowed the person to attain retirement with dignity." Or regarding his/her position in the company: "I would have strived to find a solution whereby the employee could have continued working (somewhere) until retirement." The uncertain responses reflected relational legitimacy by referring to the situational factors and their importance in managerial decision-making: "Understanding the whole situation is primarily important; the word 'easy' doesn't quite fit in this situation."

In the Italian data, relational legitimacy was the second most commonly used form of argumentation in the disagreeing responses. Relational legitimacy in the Italian data primarily referred to the future employability status of the dismissed employee. However, all three categories of responses (agreeing, disagreeing, and uncertain) referred to the age 
of the employee. Only one agreeing response used relational legitimacy: "If I had to reduce staff for overcapacity, I would favour younger people at the expense of older people." Similarly, in the disagreeing responses, managers evaluated the CEO's decision considering the consequences of the action for the dismissed employee. Italian managers asserted: "I would have dismissed the younger employee, who has more possibilities for finding another job." Or even: "I would have looked for other ways to save money, or I would have dismissed an employee at the beginning of his/her career." Moreover, disagreeing managers also considered the contribution of the employee: "I would have considered the employment status of the employee, and I would have evaluated his working life with the company and the contribution he made to the success of the organization." This suggests that for Italian managers, taking care of the employees is as important as taking care of the company's interests. Finally, there were also uncertain responses such as: "I'm neutral here because of the lack of sufficient information to reach a judgment. Obviously, I think that in these cases you can find solutions that have mutual benefit." This was said with regard to uncertainty about a decision that may damage the employee. Table 5 depicts how the relational legitimacy was used in the Finnish and Italian responses.

Table 5 Relational legitimacy in the two datasets

\begin{tabular}{|c|c|c|}
\hline Dataset & Description & Example quotes \\
\hline \multirow[t]{3}{*}{$\begin{array}{l}\text { Finnish data } \\
10 \text { responses } \\
(19 \%)\end{array}$} & \multirow{3}{*}{$\begin{array}{l}\text { The decision is } \\
\text { legitimated by } \\
\text { considering the } \\
\text { employee's situation. }\end{array}$} & $\begin{array}{l}\text { "If the alternative is to dismiss a younger employee, } \\
\text { I'll accept this. It naturally depends on the } \\
\text { motivation of this older employee." }\end{array}$ \\
\hline & & $\begin{array}{l}\text { "I would have searched for a solution that allowed } \\
\text { the person to attain retirement with dignity." }\end{array}$ \\
\hline & & $\begin{array}{l}\text { "Understanding the whole situation is primarily } \\
\text { important; the word 'easy' doesn't quite fit in this } \\
\text { situation." }\end{array}$ \\
\hline \multirow[t]{3}{*}{$\begin{array}{l}\text { Italian data } \\
47 \text { responses } \\
(21 \%)\end{array}$} & \multirow{3}{*}{$\begin{array}{l}\text { The decision is } \\
\text { evaluated based on the } \\
\text { future employability of } \\
\text { the employee, } \\
\text { especially in the case } \\
\text { of the employee who } \\
\text { is close to retirement. }\end{array}$} & $\begin{array}{l}\text { "If I had to reduce staff for overcapacity, I would } \\
\text { favour younger people at the expense of older } \\
\text { people." }\end{array}$ \\
\hline & & $\begin{array}{l}\text { "I would have dismissed the younger employee, who } \\
\text { has more possibilities of finding another job." }\end{array}$ \\
\hline & & $\begin{array}{l}\text { "I'm neutral here because of the lack of sufficient } \\
\text { information. Obviously, I think that in these cases } \\
\text { you can find solutions that have mutual benefit." }\end{array}$ \\
\hline
\end{tabular}

Source: Compiled by the authors

\subsection{Moral legitimacy}

Interestingly, pure moral argumentation was used less often than the other forms of legitimation in both datasets. In the Finnish responses, moral argumentation related to deontological thinking (i.e., it was the manager's duty to act in a certain way). Moreover, it referred to external facts more often than to the respondent's own morality. Similar to other forms of legitimacy, moral legitimacy was used in agreeing, disagreeing and uncertain responses. In the agreeing responses, moral argumentation referred to the CEO's duty: "The duty of a CEO is to execute even the unfortunate decisions if there are no other concrete options." In the disagreeing responses, the argumentation referred to 
general principles: "I would follow the general dismissal order, i.e. the last person hired will be dismissed, if necessary." Or "I would have looked for other options so that he/she could have continued until retirement." In uncertain responses, moral argumentation referred to law and rulings: "In a dismissal situation, law and statutes are always followed to the letter."

In the Italian data, when using moral legitimacy, managers evaluated the decision relying on their own morality. The Italian managers did not use moral legitimacy very often, and when they did, they referred to a personal judgement or belief regarding the dismissed employee's employability. In the agreeing responses, only three managers relied on moral legitimacy, arguing that the choice was morally acceptable given the company's situation: "I would have acted in the same way. If this is the only way to save the company, I think it is morally acceptable." The disagreeing responses relied more on moral legitimacy. In general, the action was considered unacceptable from a moral point of view: "It is a cruel act and perhaps unnecessary." The main reason for this consideration was the difficulty of finding a new job for an employee with only three years remaining before retirement. This led managers to consider the action unfair: "The action is not fair. The CEO shows that the company does not care about its employees." Finally, moral legitimacy was most used in the uncertain responses: "I would have wanted a fair solution for both parties." Or: "An ugly and painful decision. I hope it does not ever happen to me." Table 6 depicts how the moral legitimacy was used in the Finnish and Italian responses.

Table 6 Moral legitimacy in the two datasets

\begin{tabular}{|c|c|c|}
\hline Dataset & Description & Example quotes \\
\hline \multirow[t]{4}{*}{$\begin{array}{l}\text { Finnish data } \\
5 \text { responses } \\
(10 \%)\end{array}$} & \multirow{4}{*}{$\begin{array}{l}\text { The decision is } \\
\text { legitimated with moral } \\
\text { correctness. For } \\
\text { example, the } \\
\text { managing directors are } \\
\text { morally obliged to } \\
\text { follow their duties or } \\
\text { the law and therefore } \\
\text { the decision is } \\
\text { legitimate. }\end{array}$} & $\begin{array}{l}\text { "The duty of a CEO is to execute even the } \\
\text { unfortunate decisions if there are no other concrete } \\
\text { options." }\end{array}$ \\
\hline & & $\begin{array}{l}\text { "I would follow the general dismissal order (i.e. the } \\
\text { last person hired will be dismissed, if necessary)." }\end{array}$ \\
\hline & & $\begin{array}{l}\text { Or "I would have looked for other options so that } \\
\text { (s)he could have continued until retirement." }\end{array}$ \\
\hline & & $\begin{array}{l}\text { "In a dismissal situation, law and statutes are always } \\
\text { followed to the letter." }\end{array}$ \\
\hline \multirow[t]{3}{*}{$\begin{array}{l}\text { Italian data } \\
19 \text { responses } \\
(9 \%)\end{array}$} & \multirow[t]{3}{*}{$\begin{array}{l}\text { The decision is } \\
\text { evaluated based on } \\
\text { moral judgements. }\end{array}$} & $\begin{array}{l}\text { "I would have acted in the same way. If this is the } \\
\text { only way to save the company, I think it is morally } \\
\text { acceptable." }\end{array}$ \\
\hline & & $\begin{array}{l}\text { "The action is not fair. The CEO shows that the } \\
\text { company does not care about its employees." }\end{array}$ \\
\hline & & "I would have wanted a fair solution for both parties." \\
\hline
\end{tabular}

Source: Compiled by the authors

\section{Discussion}

The clear differences between the two countries' responses in this study can be related to the cultural dimensions and differences (Hofstede, 1984; Hofstede et al., 2005; Hofstede Insights, 2019) as well as to the different views of legitimacy suggested by Suddaby et al. 
(2017). Firstly, cognitive legitimacy was the most common method of argumentation both in Finland and in Italy. However, in the Finnish data, cognitive legitimacy was used most often in the agreeing responses, while the Italian respondents used cognitive legitimacy in the disagreeing responses. In the Finnish data, the leader was seen as an authority and therefore his/her view on the situation was seen to legitimate the agreeing decision. In the Italian data, managers showed confidence that a different solution must exist - one that may not be the simplest but could help avoid the dismissal of the employee. While both countries used cognitive legitimacy in their argumentation, the difference is that Finnish managers see legitimacy as a perception and the Italian managers as a process. Therefore, the outcome of the argumentation is different, too. The perception view fosters the individual as an authority who can make the decision and, thus, reflects the short-term orientation and normative dimension of the Finnish culture with great respect for traditions and focus on achieving quick results. Whereas, the process view enhances the interaction and collaboration in finding a better solution and demonstrates the long-term orientation and pragmatic dimension of the Italian culture.

Instrumental legitimacy was the second most commonly used method in both Finnish and Italian responses. The decision was legitimated, for example, with the benefit of the company or the preservation of other jobs. The Finnish respondents used instrumental legitimacy to argue that the managing director is obliged to advocate the company's interests and dismiss the employee in this kind of a situation. This refers to the property view of legitimacy as the argumentation relies on organisational and situational factors as well as to the short-term orientation and normative dimension of the Finnish culture. In the Italian data, however, instrumental legitimacy was used in the disagreeing responses to argue that such a decision must not be based only on the economic interests of the company but also must consider the consequences on the organisational climate in terms of motivation and trust in the organisation. Contradictory to the Finnish argumentation, the Italian argumentation relates again to the process view of legitimacy as it sees the consequences of the action as important in terms of decision-making reflecting the long-term orientation and pragmatic dimension of the Italian culture.

Relational legitimacy was more common in disagreeing responses than in agreeing on responses both in Finland and in Italy. Negotiating with and listening to the employee is important for legitimating the response. In the Finnish data, however, taking care of the business is more common than taking care of the employees, while, in the Italian data, taking care of the employees is part of the argumentation almost to the same extent as taking care of the company's interests. Moreover, Italian respondents considered the consequences for the dismissed employee with special regard for the employee's age. Again, the differences relate to the long-term vs. short-term orientation of the culture as well as to the different views of legitimacy. While both countries show the process view to some extent, the Finnish argumentation relates more heavily to the property view and short-term orientation, whereas the Italian argumentation relates to the perception view and long-term orientation.

Surprisingly, moral legitimacy was seldom used in either country. In the Finnish data, some respondents referred to deontological thinking, but the argumentation referred more often to external facts than to the respondent's own morality. In Italy, the argumentation was based on the respondent's own morality and on a personal judgement or belief regarding the dismissed employee's employability. The action was considered cruel since an employee three years before retirement would have difficulty finding a new job. Here, 
the Finnish argumentation relates again to the property view and short-term orientation while the Italian argumentation shows elements of the process view and long-term cultural orientation.

\section{Theoretical contributions and managerial implications}

As a first contribution, this study responds to the call for qualitative research of moral decision-making (Brand and Slater, 2003) and increases our understanding of how managers use different forms of argumentation when making moral decisions. The study shows that cognitive and instrumental reasoning are more common in managerial decision-making than relational or moral argumentation. Moreover, the study also shows that managers use cognitive and instrumental legitimation for both agreeing and disagreeing responses. This leads to the conclusion that the content of the argumentation is heavily related to the contextual factors, and that we need to understand the differences between various cultures to comprehend the different forms of legitimacy argumentation.

The second contribution relates to the comparison of cultural differences in moral decision-making and the question of how cultural values influence moral decisions (Fok et al., 2016). Based on this study, it seems that both countries' social systems affect managerial argumentation. This aspect appears to be fundamental for the depicted scenario, especially for the employee with three years remaining before retirement. The Finnish respondents seem to believe that the social system will take care of such an employee, while in the Italian data, the respondents feel it is the duty of the company and the manager him/herself to take care of the older employee. Italians also showed much more care about not only the financial interests of the company but also the organisational climate and the impact of such a decision on motivation and trust towards the organisation.

Finally, the study shows that the differences between Finnish and Italian managers decision-making can be explained with different ways of using legitimacy combined with the short-term vs. long-term orientation of the culture. Finnish managers use the property and perception views of legitimacy that reflect the short-term orientation and normative dimension of the culture, while Italian managers rely more on a process view of legitimacy reflecting the long-term orientation in their decision-making.

As a managerial contribution, the authors argue that the cultural aspect and its influence on managerial legitimation in moral decision-making is something that organisations and their managers should be aware of in the era when internationalisation and globalisation are apparent in almost all businesses. Being able to discuss cultural differences and understanding the ways by which cultural factor relate to moral decisions will help to overcome organisational and individual disagreements.

\section{Conclusions}

This study examined the influence of cultural context in managerial decision-making by comparing the legitimacy views of Finnish and Italian business managers. The authors collected data from Finland and Italy by depicting a moral dilemma in which an older employee was dismissed. The authors used legitimacy theory and argumentation analysis to analyse the data. The findings of the study show significant differences in the 
managerial legitimation of the two countries and increase our understanding of how managers use different methods of argumentation and views of legitimacy in moral decision-making.

\section{Acknowledgements}

The authors gratefully acknowledge the financial support from the Finnish Foundation of Economic Education.

\section{References}

Berger, P.L. and Luckmann, T. (1966) The Social Construction of Reality: A Treatise in the Sociology of Knowledge, Doubleday, Garden City, NY.

Bitektine, A. and Haack, P. (2015) 'The macro and the micro of legitimacy: towards a multi-level theory of the legitimacy process', Academy of Management Review, Vol. 40, No. 1, pp.49-75.

Brand, V. and Slater, A. (2003) 'Using a qualitative approach to gain insights into the business ethics experiences of Australian managers in China', Journal of Business Ethics, Vol. 45, No. 3, pp.167-182.

Craft, J.L. (2013) 'A review of the empirical ethical decision-making literature: 2004-2011', Journal of Business Ethics, Vol. 117, No. 2, pp.221-259.

Chen, H.Y., Griffith, D.A. and Hu, M.Y. (2006) 'The influence of liability of foreignness on market entry strategies', International Marketing Review, Vol. 23, No. 6, pp.636-649.

Deegan, C. (2006) 'Legitimacy theory', in Hoque, Z. (Ed.): Methodological Issues in Accounting Research: Theories, Methods and Issues, Spiramus Press, London.

Deephouse, D.L., Bundy, J., Tost, L.P. and Suchman, M.C. (2017) 'Organizational legitimacy: six key questions', in Greenwood, R., Oliver, C., Lawrence, T.B. and Meyer, R.E. (Eds.): The SAGE Handbook of Organizational Institutionalism, pp.27-54, Sage, London.

Ferrell, O.C. and Gresham, L.G. (1985) 'A contingency framework for understanding ethical decision making in marketing', The Journal of Marketing, Vol. 49, No. 3, pp.87-96.

Foucault, M. (2002) The Archaeology of Knowledge, in Smith, A.M.S. (Trans.), Routledge, London, original work published in 1969.

Fok, L.Y., Payne, D.M. and Corey, C.M. (2016) 'Cultural values, utilitarian orientation, and ethical decision making: a comparison of US and Puerto Rican professionals', Journal of Business Ethics, Vol. 134, No. 2, pp.263-279.

George, E., Chattopadhyay, P., Sitkin, S.B. and Barden, J. (2006) 'Cognitive underpinnings of institutional persistence and change: a framing perspective', Academy of Management Review, Vol. 31, No. 2, pp.347-365.

Gioia, D.A., Corley, K.G. and Hamilton, A.L. (2013) 'Seeking qualitative rigor in inductive research: notes on the Gioia methodology', Organizational Research Methods, Vol. 16, No. 1, pp.15-31.

Hofstede Insights (2019) Country Comparison [online] https://www.hofstede-insights.com/countrycomparison/finland, italy/ (accessed 9 March 2019).

Hofstede, G. (1984) Culture's Consequences: International Differences in Work-related Values, Sage, Beverly Hills.

Hofstede, G. (1985) 'The interaction between national and organizational value systems', Journal of Management Studies, Vol. 22, No. 4, pp.347-357.

Hofstede, G., Hofstede, G.J. and Minkov, M. (2005) Cultures and Organizations: Software of the Mind, Vol. 2, Mcgraw-Hill, New York. 
Hsieh, H.F. and Shannon, S.E. (2005) 'Three approaches to qualitative content analysis', Qualitative Health Research, Vol. 15, No. 9, pp.1277-1288.

Hunt, S.D. and Vitell, S. (1986) 'A general theory of marketing ethics', Journal of Macromarketing, Vol. 6, No. 1, pp.5-16.

Joutsenvirta, M. and Vaara, E. (2009) 'Discursive (de) legitimation of a contested Finnish greenfield investment project in Latin America', Scandinavian Journal of Management, Vol. 25, No. 1, pp.85-96.

Kujala, J. (2001) 'A multidimensional approach to Finnish managers' moral decision-making', Journal of Business Ethics, Vol. 34, Nos. 3-4, pp.231-254.

Kujala, J., Lämsä, A.M. and Penttilä, K. (2011) 'Managers' moral decision-making patterns over time: a multidimensional approach', Journal of Business Ethics, Vol. 100, No. 2, pp.191-207.

Lehnert, K., Craft, J., Singh, N. and Park, Y.H. (2016) 'The human experience of ethics. a review of a decade of qualitative ethical decision-making research', Business Ethics: A European Review, Vol. 25, No. 4, pp.498-537.

Loe, T.W., Ferrell, L. and Mansfield, P. (2000) 'A review of empirical studies assessing ethical decision making in business', Journal of Business Ethics, Vol. 25, No. 3, pp.185-204.

Lu, L.C., Rose, G.M. and Blodgett, J.G. (1999) 'The effects of cultural dimensions on ethical decision making in marketing: an exploratory study', Journal of Business Ethics, Vol. 18, No. 1, pp.91-105.

O'Fallon, M.J. and Butterfield, K.D. (2005) 'A review of the empirical ethical decision-making literature: 1996-2003', Journal of Business Ethics, Vol. 59, No. 4, pp.375-413.

Oumlil, A.B. and Balloun, J.L. (2009) 'Ethical decision-making differences between American and Moroccan managers', Journal of Business Ethics, Vol. 84, No. 4, pp.457-478.

Patriotta, G., Gond, J. and Schultz, F. (2011) 'Maintaining legitimacy: controversies, orders of worth, and public justifications', Journal of Management Studies, Vol. 48, No. 8, pp.1804-1836.

Payne, D., Corey, C.M. and Fok, L.Y. (2016) 'The indirect effects of cultural values on ethical decision making via utilitarian ethical orientation', American Journal of Management, Vol. 16, No. 1, p.19.

Rieke, R.D., Sillars, M.O. and Peterson, T.R. (2013) Argumentation and Critical Decision Making, Pearson Education, Boston.

Sims, R.L. (2009) 'Collective versus individualist national cultures comparing Taiwan and US employee attitudes toward unethical business practices', Business and Society, Vol. 48, No. 1, pp.39-59.

Suddaby, R., Bitektine, A. and Haack, P. (2017) 'Legitimacy', Academy of Management Annals, Vol. 11, No. 1, pp.451-478.

Suchman, M.C. (1995) 'Managing legitimacy: strategic and institutional approaches', The Academy of Management Review, Vol. 20, No. 3, pp.571-610.

Tost, L.P. (2011) 'An integrative model of legitimacy judgments', Academy of Management Review, Vol. 36, No. 4, pp.686-710.

Treviño, L.K., den Nieuwenboer, N.A., Kreiner, G.E. and Bishop, D.G. (2014) 'Legitimating the legitimate: a grounded theory study of legitimacy work among ethics and compliance officers', Organizational Behavior and Human Decision Processes, Vol. 123, No. 2, pp.186-205.

Triandis, H.C. (1995) Individualism and Collectivism, Westview Press, Boulder. 